\title{
Distanciamento social durante a pandemia de COVID-19: Impactos no cotidiano acadêmico e na saúde mental de estudantes de terapia ocupacional
}

\author{
Teresinha Cid Constantinidis \\ Professora do Departamento de Terapia Ocupacional da Universidade Federal do Espírito Santo - UFES, do \\ Programa de Pós-Graduação em Terapia Ocupacional da Universidade Federal de São Carlos-UFSCar e do \\ Programa de Pós-Graduação em Psicologia da UFES \\ $\triangle$ teracidc@gmail.com

\section{Thelma Simões Matsukura} \\ Professora do Programa de Pós-Graduação em Terapia Ocupacional da Universidade Federal de São Carlos- \\ UFSCar
}

Recebido em 24 de fevereiro de 2021

Aceito em 8 de setembro de 2021

\begin{abstract}
Resumo:
Diante a pandemia da COVID-19, estudantes universitários foram sujeitos à suspensão das aulas presenciais, impedindo o convívio acadêmico, trazendo preocupações quanto às atividades práticas e ao tempo de formação, podendo conduzir a uma vulnerabilidade da saúde mental destas pessoas. Estudos anteriores ao período pandêmico trazem o grupo de estudantes de terapia ocupacional afetado em prejuízos a sua saúde mental. Este estudo objetivou conhecer os impactos do período de pandemia COVID-19 e distanciamento social no percurso acadêmico e no cotidiano de estudantes de terapia ocupacional, assim como os níveis de depressão, ansiedade e estresse entre este grupo de jovens. Participaram 235 estudantes de terapia ocupacional de universidades de todo o país, que responderam formulário on-line, composto de Questionário de Vivências Acadêmicas em Terapia Ocupacional (QUESVATO) e de Depression, Anxiety and Stress Scale, (DASS-21). Os dados foram analisados estatisticamente e por meio do software IRAMUTEQ. Os resultados indicam como fatores desencadeantes de sofrimento emocional/psíquico a falta do cotidiano acadêmico pré pandemia, preocupação com as atividades acadêmicas, dificuldade de acompanhamento do ensino remoto, preocupação financeira e com familiares. Os índices de depressão, ansiedade e stress apresentados por estes/estas estudantes são relacionados ao momento de isolamento social e suas repercussões. Foi apontada a importância do rastreamento de estados emocionais, assim como limites e possibilidades no acompanhamento de aulas nas modalidades síncronas e assíncronas utilizadas no ensino remoto emergencial, para o planejamento e elaboração de plano de cuidado, e prestação de assistência psicossocial, aos/ às estudantes.

Palavras-chave: COVID-19, pandemia, saúde mental, universitários, terapia ocupacional.

\section{Social distancing during the COVID-19 pandemic: Effects on academic daily life and mental health of occupational therapy students}

\begin{abstract}
:
Faced with the COVID-19 pandemic, university students were subjected to the suspension of face-toface classes, preventing academic interaction, raising concerns about practical activities and training time, which could lead to the vulnerability of these people's mental health. Studies prior to the pandemic period bring the group of occupational therapy students affected in damage to their mental
\end{abstract}


health. This study aimed to know the effects of the pandemic period COVID-19 and social distance in the academic path and in the daily life of students of occupational therapy, as well as the levels of depression, anxiety and stress among this group of young people. 235 occupational therapy students from universities across the country participated, who answered an online form, consisting of the Questionnaire on Academic Experiences in Occupational Therapy (QUESVATO) and the Depression, Anxiety and Stress Scale, (DASS-21). The data were analyzed statistically and using the software IRAMUTEQ. The results indicate as factors that trigger emotional / psychic suffering the lack of prepandemic academic daily life, concern with academic activities, difficulty in monitoring remote education, financial and family concerns. The rates of depression, anxiety and stress presented by these students are related to the moment of social isolation and its repercussions. It was pointed out the importance of tracking emotional states, as well as limits and possibilities in the monitoring of classes in synchronous and asynchronous modalities used in remote emergency teaching, for planning and elaborating a care plan, and providing psychosocial assistance to students.

Keywords: COVID-19, pandemic, mental health, university students, occupational therapy.

\section{Aislamiento social durante la pandemia de COVID-19: Efectos sobre la vida académica diaria y la salud mental de los estudiantes de terapia ocupacional}

\section{Resumen:}

Frente a la pandemia COVID-19, los estudiantes universitarios fueron sometidos a la suspensión de las clases presenciales, lo que podría conducir a la vulnerabilidad de la salud mental de estas personas. Estudios previos al período pandémico traen al grupo de estudiantes de terapia ocupacional afectados en daño a su salud mental. Este estudio tuvo como objetivo conocer los efectos del período pandémico COVID-19 y la distancia social en la trayectoria académica y en la vida diaria de los estudiantes de terapia ocupacional, así como los niveles de depresión, ansiedad y estrés en este grupo de jóvenes. Participaron 235 estudiantes de terapia ocupacional, quienes respondieron un formulario en línea, compuesto por el Cuestionario de Experiencias Académicas en Terapia Ocupacional (QUESVATO) y la Escala de Depresión, Ansiedad y Estrés, (DASS-21). Los datos fueron analizados estadísticamente y utilizando el software IRAMUTEQ. Los resultados señalan como factores desencadenantes del sufrimiento emocional la falta de cotidianidad académica prepandémica, la preocupación por las actividades académicas, la dificultad en el seguimiento de la educación a distancia, las preocupaciones económicas y familiares. Los índices de depresión, ansiedad y estrés que presentan estos estudiantes están relacionados con el momento de aislamiento social y sus repercusiones. Se señaló la importancia del seguimiento de los estados emocionales, así como los límites y posibilidades en el seguimiento de las clases en modalidades sincrónicas y asincrónicas utilizadas en la enseñanza a distancia de emergencia, para la planificación y elaboración de un plan de atención y la prestación de asistencia psicosocial a los estudiantes.

Palabras clave: COVID-19, pandemia, salud mental, estudiantes universitarios, terapia ocupacional.

\section{INTRODUÇÃO}

Desde 30 de janeiro de 2020 a Organização Mundial de Saúde (OMS) declarou que o surto pandêmico do COVID-19, doença infecciosa altamente contagiosa causada pelo novo coronavírus (SARS-CoV-2), constitui uma Emergência de Saúde Pública de Importância Internacional (ESPII) - o mais alto nível de alerta da Organização (OMS, 2020). Trata-se de um surto sem precedentes, uma das maiores epidemias da história, com efeitos sociais, culturais, econômicos e educacionais para os quais o mundo não estava preparado (ARRUDA, 2020). 
Para prevenir a propagação do COVID-19, dentre outras medidas clássicas de saúde pública, está sendo utilizado o distanciamento social (VALI et al, 2020), que é uma medida adotada em vários países, inclusive no Brasil, que inclui a abstenção de encontros e de contato com pessoas fora do convívio próximo, evitando-se aglomerações procurando-se manter distância mínima de um metro e meio para outras pessoas (WILLIANS et al, 2020).

Estima-se que mais de um terço da população global esteja adotando o distanciamento como medida, com o fechamento de escolas, universidades e muitas instituições públicas, assim como a instituição do homeoffice em muitas empresas (MAIA e DIAS, 2020). O novo coronavírus torna a escola um dos espaços mais temidos pelo risco da transmissão e as políticas mundiais de retorno às atividades coletivas têm deixado as atividades escolares em último plano (UNESCO, 2020).

É importante destacar que o distanciamento social vem afetando a vida coletiva ou individual, com repercussões na saúde mental da população. Nesta situação, o número de pessoas afetadas psicologicamente, que podem apresentar consequências psicológicas ou psiquiátricas costuma ser maior que o de pessoas acometidas pela infecção (LIMA, 2020).

Em relação ao ensino superior no Brasil, o Ministério da Educação publicou a Portaria n. 343 em 17 de março de 2020 que estabeleceu diretrizes para ampliar a modalidade a distância de forma emergencial (BRASIL, 2020). Destaca-se que o ensino a distância requer o acesso a equipamentos adequados e internet banda larga para o acesso às plataformas de ensino, além de ambiente doméstico adequado para as aulas on-line e atividades didáticas, condições inexistentes para parte de estudantes que, desta forma, são excluídos desta possibilidade de ensino.

Assim, além dos fatores de stress que a população está sujeita como: receio em relação ao vírus, à contaminação, às perdas de pessoas queridas, frustração, diminuição de rendimentos, etc., estudantes universitários foram sujeitos à suspensão das aulas presenciais, implantação do ensino a distância que, além de questões inerentes destacadas, impedem o convívio diário com colegas, professores e comunidade universitária. A estas circunstancias somam-se preocupações em relação às aulas práticas, aos estágios e aos atrasos quanto ao tempo de formação. A adaptação a estas circunstancias pode não ser bem-sucedida, 
emergindo conflitos de várias ordens, trazendo sofrimento, conduzindo a uma vulnerabilidade da saúde mental (LIMA, 2020).

Ressalta-se que para além da crise pandêmica e seus efeitos na vida dos estudantes universitários, nos últimos anos, a saúde mental de estudantes vem sendo foco de preocupação social pela elevada prevalência de transtornos mentais entre este grupo de jovens (ORELLANA et al, 2020). Estudos de Ibrahim et al. (2013), de Leão et al, (2018), assim como pesquisa realizada pelo Forum Nacional de Pró-reitores de Assuntos Comunitários e Estudantis (FONAPRACE, 2018) apontam que esta prevalência é maior se comparada a jovens não estudantes. O sofrimento psíquico entre os estudantes manifesta seus efeitos por meio de estresse, ansiedade, depressão, drogadição, suicídio, assim como altos índices de reprovação, trancamento e evasão (GONÇALVES e AMBAR, 2015).

No que diz respeito à pandemia pelo COVID-19 e a saúde mental de estudantes universitários, em revisão preliminar da literatura, verifica-se que o impacto psicológico causado pela pandemia de COVID-19 tem sido um disruptor crítico causando, nas/nos estudantes, transtornos de ansiedade e depressivo entre outros (ARAÚJO et al, 2020; CAO et al, 2020; KECOJEVIC et al, 2020; SILVA et al, 2020; WANG et al, 2020). São raros os estudos nacionais sobre a temática e, especificamente, não há notícias de estudos que exploraram os impactos da COVID-19 e do distanciamento social sobre a saúde mental de estudantes de terapia ocupacional.

O curso de Terapia Ocupacional tem predominância de mulheres entre seu grupo de estudantes, com 90\% de alunas do sexo feminino (Brasil. Ministério da Educação. SINAES, 2004). Este dado converge com a maior representatividade feminina no ensino superior no Brasil, que representa 71,3\% das matrículas totais de estudantes universitários (BRASIL, 2019).

Em relação ao fato de ter grande número de estudantes mulheres, destaca-se que o sexo feminino traz resultados piores na saúde mental, se comparado ao sexo masculino, com diferenças significantes em relação à presença de Transtornos Mentais Comuns e stress, conforme indicam estudos de Ferreira et al (2016), Jansen et al (2011) e Medeiros et al (2018). Além disso, estudos apontam que os transtornos mentais estão associados a uma probabilidade significativamente aumentada, não só ao sexo feminino, mas também ao baixo nível socioeconômico (ANDRADE et al., 2012; SCHWARTZ et al., 2011). 
Pesquisa do FONAPRACE (2018) aponta que 70,2\% de estudantes de universidades federais estão inseridos na faixa de renda mensal familiar per capita até um e meio salários mínimos. Neste sentido, é importante destacar que o número de estudantes em condição socioeconômica precária vem aumentando nas universidades, graças a democratização e expansão do acesso, por meio Programa de Apoio a Planos de Reestruturação e Expansão das Universidades Federais (REUNI), a partir de 2007, e estratégias de garantia de permanência de grupos historicamente discriminados nas instituições universitárias, por meio da implementação de políticas de ações afirmativas. No curso de terapia ocupacional, a despeito de não ter sido encontrado dado atual sobre o perfil socioeconômico de seus estudantes, é possível, em observação informal, ser verificado que boa parte dos/das estudantes são provenientes de classe socioeconômica baixa ou até em situações de vulnerabilidade. À exemplo, na Universidade Federal da Paraíba (UFPB), 47\% de estudantes deste curso possuem renda familiar de zero a dois salários mínimos (BORBA et al, 2020).

Estas variáveis de gênero e situação socioeconômica, em relação ao curso de terapia ocupacional integram, juntamente com a sobrecarga que o curso traz ao alunato (GOVENDER et al, 2016; SANCHES et al, 2018; WITT et al, 2019), fatores que podem trazer prejuízos à saúde mental $\mathrm{da} /$ do estudante. Os estudos atribuem ao período de estágio ou à sobrecarga gerada pelas atividades acadêmicas do curso de terapia ocupacional como fatores estressores. No entanto, o estágio curricular, assim como os encargos decorrentes das atividades acadêmicas são também fatores estressores presentes em outros cursos da área da saúde (MURAKAMI et al, 2019; NERDRUM et al 2009), não sendo problemas específicos à formação em terapia ocupacional.

Com a pandemia e suas repercussões, ressalta-se a importância de estudos sobre a saúde mental de estudantes universitários, no sentido de colaborar para ações de atenção, cuidado e promoção de saúde mental deste grupo de jovens. Ao abordar tal tema com estudantes de terapia ocupacional, cuja caracterização mostra-se próxima, comum, ao grupo ampliado de estudantes universitários, busca-se contribuir também com os estudos e ações de saúde mental de acadêmicos de outros cursos e com seus formadores. Dessa forma, este estudo objetiva conhecer os impactos do período de pandemia COVID-19 e distanciamento social no percurso acadêmico e no cotidiano de estudantes de terapia ocupacional, assim como os níveis de depressão, ansiedade e estresse entre este grupo de jovens. 


\section{MÉTODO}

Trata-se de um estudo não experimental, transversal, exploratório-descritivo, com amostra de conveniência segundo a participação voluntária durante o período de coleta de dados.

\section{Participantes}

A amostra é constituída por estudantes de terapia ocupacional de diferentes instituições de ensino superior, de diferentes regiões do Brasil. Participaram 235 estudantes, sendo 99,05\% oriundos de Instituição de Ensino Superior (IES) pública e 0,05\% oriundos de IES particular. Em relação ao período de formação no curso, 34,9\% encontra-se nos períodos iniciais (entre o primeiro e o terceiro semestre), 34\% encontra-se em períodos intermediários (entre o quarto ao sexto semestre) e $31 \%$ encontra-se nos períodos finais de estudo (entre o sétimo e décimo semestre).

A caracterização sociodemográfica dos participantes é apresentada na Tabela 1, segundo sexo, cor, situação civil e renda média do núcleo familiar.

Tabela 1 - Caracterização sociodemográfica dos participantes

\begin{tabular}{lll}
\hline \multirow{2}{*}{$\begin{array}{l}\text { STEM } \\
\text { SOCIODEMOGRÁFICo }\end{array}$} & CARACTERÍSTICA & $\mathbf{\%}$ \\
\hline Sexo & Feminino & 88,9 \\
\cline { 2 - 3 } & Masculino & 11,1 \\
\hline Cor & Branca & 63,8 \\
\cline { 2 - 3 } & Preta & 12,8 \\
\cline { 2 - 3 } & Parda & 17,9 \\
\cline { 2 - 3 } & Amarela & 1,7 \\
\cline { 2 - 3 } & Não se classificou & 3,8 \\
\hline Situação civil & Solteira/solteiro & 79,6 \\
\cline { 2 - 3 } & Casada/casado & 7,2 \\
\cline { 2 - 3 } & Divide moradia com & 6,0 \\
& companheiro/companheira
\end{tabular}




\begin{tabular}{|c|c|c|}
\hline & Divorciada/Divorciado & 2,1 \\
\hline & Separada/Separado & 1,7 \\
\hline & Outro & 3,4 \\
\hline \multirow{8}{*}{$\begin{array}{l}\text { Renda média do } \\
\text { núcleo familiar (em } \\
\text { salários mínimos) }\end{array}$} & menos de um & 7,2 \\
\hline & um a dois & 29,8 \\
\hline & dois a três & 22,6 \\
\hline & três a cinco & 19,3 \\
\hline & Cinco a oito & 6,8 \\
\hline & Oito a dez & 4,7 \\
\hline & Mais de 10 & 6,4 \\
\hline & Não informou & 3,0 \\
\hline
\end{tabular}

Fonte: Elaborada pelas autoras.

Antes do distanciamento social 48,5\% dos participantes residiam em repúblicas de estudantes, em alojamento estudantil, sozinha/sozinho ou com seu/sua companheiro/companheira, sendo que 45,5\% estudam em IES situadas em cidades diferentes da cidade onde habitam suas famílias. Com a mudança para aulas on-line, 34,5\% voltaram a morar com familiares, alcançando $83 \%$ de de estudantes que residem com seus familiares atualmente. A mudança ou retorno para a moradia de familiares atingiu principalmente estudantes habitantes de repúblicas e alojamentos.

Em relação ao rendimento acadêmico, Gráfico 1 apresenta autoavaliação, realizada pelos participantes, do rendimento acadêmico anterior à pandemia do COVID-19 e ao ensino remoto. 
Gráfico 1- Autoavaliação do rendimento acadêmico anterior à pandemia do COVID-19

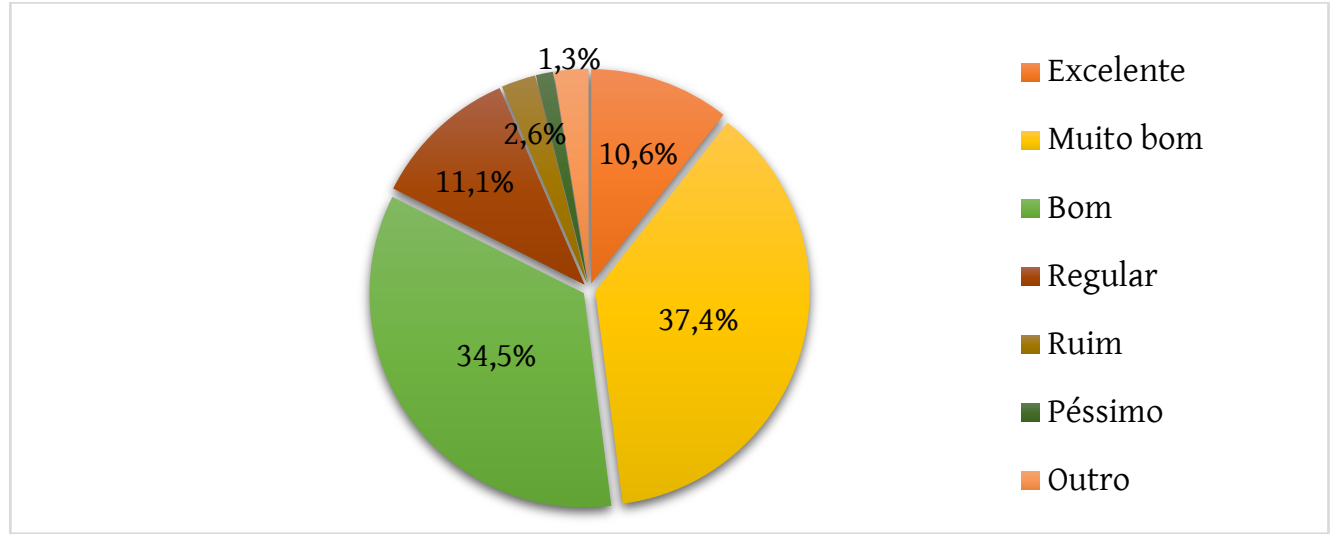

Fonte: Elaborada pelas autoras.

\section{Procedimentos}

Os procedimentos foram iniciados após aprovação do projeto, sob parecer $n^{\circ} 4.022 .960$, pelo Conselho de Ética em Pesquisa da UFES - Centro de Ciências da Saúde da Universidade Federal do Espírito Santo. A partir daí foi realizada a coleta de dados por meio de aplicação de formulário on-line (Google Forms) composto de três questionários, sendo que, no presente estudo, foram utilizados os resultados de dois deles.

Todas as coordenações de curso de terapia ocupacional, de norte a sul do país, foram contatadas, assim como centros acadêmicos, para solicitação de auxílio na divulgação da pesquisa entre os/as estudantes. $\mathrm{O}$ link de acesso ao formulário foi enviado às/aos participantes pelas/pelos colaboradores, por meio de e-mail, WhatsApp ou redes sociais. A coleta foi realizada ao longo de três meses, entre outubro e dezembro de 2019. Para acesso ao formulário, o/a participante preencheu o termo de consentimento esclarecido e teve garantido o anonimato e a confidencialidade dos dados. 0 único critério de inclusão utilizado foi ser estudante de curso de terapia ocupacional.

\section{Instrumentos}

Foram utilizados os seguintes questionários:

Questionário de Vivências Acadêmicas em Terapia Ocupacional (QUESVATO), desenvolvido pelas autoras deste estudo e avaliado e validado por pesquisadoras da área de saúde mental. Por meio de perguntas de resposta única, de múltipla escolha ou abertas, são abordadas questões relativas a sexo, cor/etnia, situação socioeconômica, além de questões relativas ao afastamento social, percurso 
acadêmico na terapia ocupacional, fatores positivos e negativos do ensino remoto e o impacto do COVID-19 na vida das/dos estudantes de terapia ocupacional.

Depression, Anxiety and Stress Scale, versão curta de 21 itens (DASS-21), desenvolvido por Lovibond e Lovibond (1995). Foi utilizada a versão traduzida e validada para o português do Brasil- por Vignola e Tucci (2013). Trata-se de instrumento avaliativo de autorresposta que contém três subescalas pontuadas em uma escala Likert de quatro pontos ( $0,1,2$ e 3$)$, variando de 0 ("Não se aplicou de maneira alguma") a 3 ("Aplicou-se muito, ou na maioria do tempo"). Cada subescala do DASS-21 consiste em sete itens que avaliam os estados emocionais de depressão, ansiedade e estresse.

\section{Análise de dados}

Foram realizadas análises estatísticas a fim de relacionar diferentes variáveis. Para o tratamento estatístico foram utilizados o programa computacional SPSS 20.0. Nas análises realizadas considerou-se um nível de significância de 5\%. Foi verificada a suposição de normalidade na distribuição dos dados por meio do teste de normalidade Kolmogorov Smirnov. Dado que o teste apontou que as variáveis utilizadas possuem distribuição normal, utilizou-se o teste T para comparar as médias dos grupos, no caso os dados do DASS e dados sociodemográficos do QUESVATO.

Os dados qualitativos, resultantes da análise de questão aberta do QUESVATO foram analisados com auxílio do software IRaMuTeQ (Interface de $\mathrm{R}$ pour les Analyses Multidimensionnelles de Textes et de Questionnaires), que consiste em um "programa informático gratuito, que permite diferentes formas de análises estatísticas sobre corpus textuais e sobre tabelas de indivíduos por palavras" (CAMARGO e JUSTO, 2013, p. 513). O material textual obtido por meio da questão aberta foi transcrito em um corpus, e submetido a uma Classificação Hierárquica Descendente (CHD), análise realizada pelo Software IRaMuTeQ, resultando na construção de dendrograma (CAMARGO e JUSTO, 2013) que informa, entre outras análises, a distribuição das classes, classificando os segmentos de texto de acordo com seus vocabulários. Além disso, o software permite que os segmentos de texto associados a cada classe sejam recuperados no corpus original. 


\section{RESULTADOS}

Primeiramente serão apresentados os resultados advindos da avaliação dos estudantes sobre aspectos negativos do ensino remoto emergencial, assim como os aspectos positivos. Na sequência, será apresentado a autoavaliação do estado psíquico dos estudantes e as situações estressantes que geram sofrimento emocional e/ou psíquico entre eles. Finalizando a apresentação dos resultados, serão apresentados os índices do DASS-21 para este grupo e a correlação com dados sociodemográficos e rendimento acadêmico.

Em relação aos aspectos negativos do ensino remoto emergencial, o Gráfico 2 apresenta os principais aspectos negativos deste tipo de ensino, na visão de alunas e alunos:

Gráfico 2 - Aspectos negativos do ensino remoto emergencial

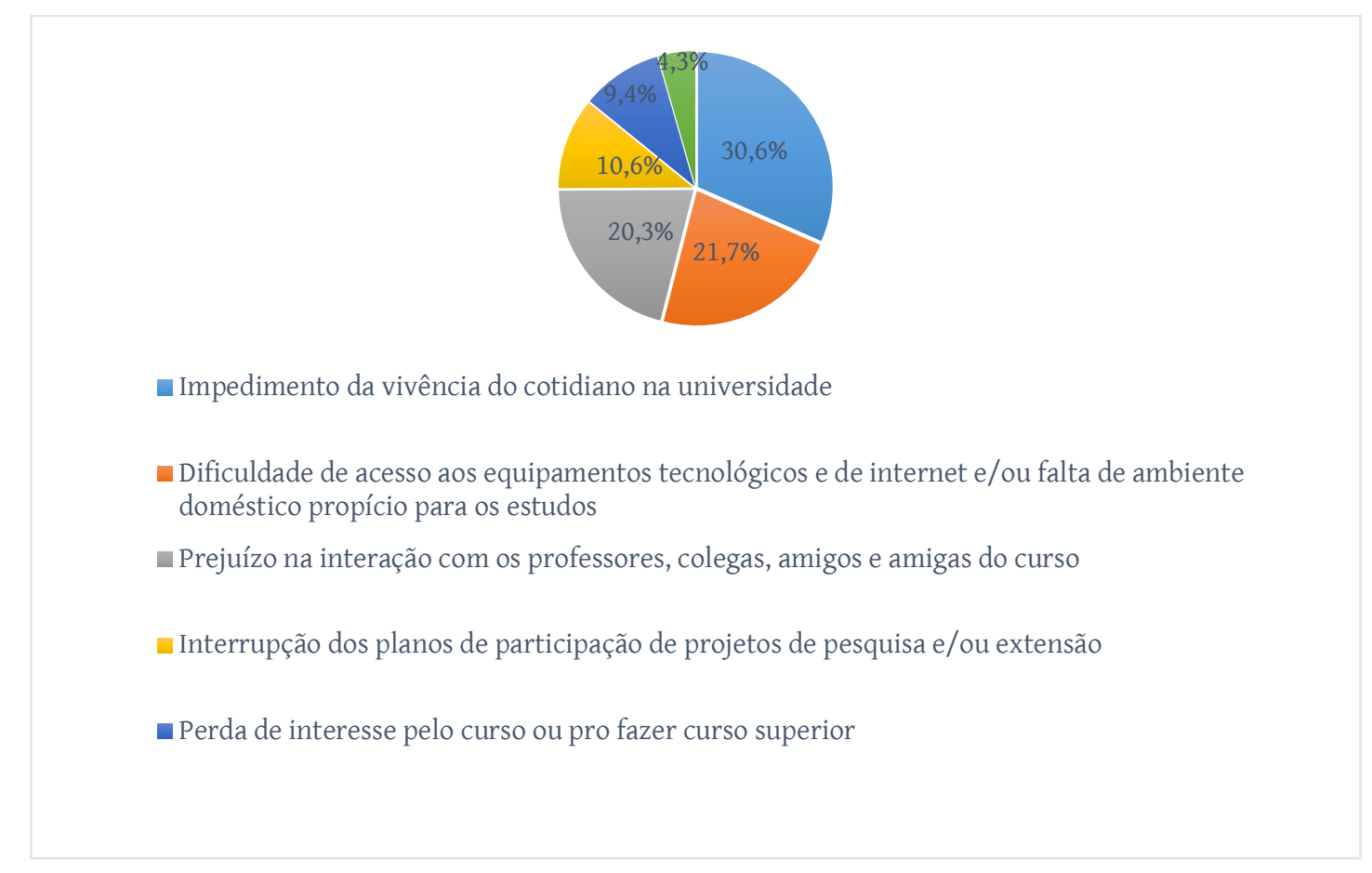

Fonte: Elaborada pelas autoras.

Se por um lado, existem aspectos negativos decorrentes do ensino à distância pelo distanciamento social, por outro lado, existem também aspectos positivos, conforme resultados apresentados no Gráfico 3: 
Distanciamento social durante a pandemia de COVID-19: Impactos no cotidiano acadêmico e na saúde mental de estudantes de terapia ocupacional

Gráfico 3 - Aspectos positivos do ensino remoto emergencial

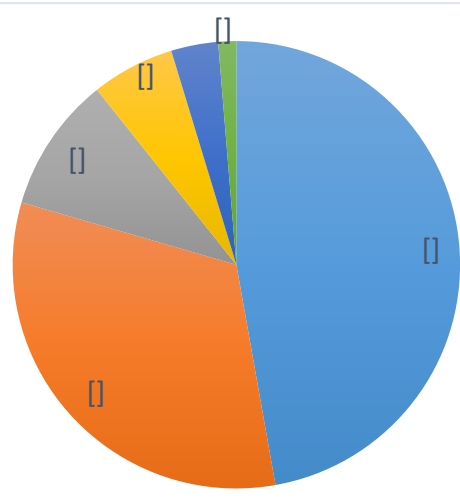
— Possibilidade de escolha/adaptação de horário n Não tem aspecto positivo
- Maior tempo de dedicação aos estudos
Outro
- Distância do ambiente universitário
- Interação limitada com colegas e professores

Fonte: Elaborada pelas autoras.

O Gráfico 4 apresenta como as/os estudantes referem estar se sentindo diante da pandemia e do distanciamento social.

Gráfico 4 - Autoavaliação do estado psíquico dos/das estudantes

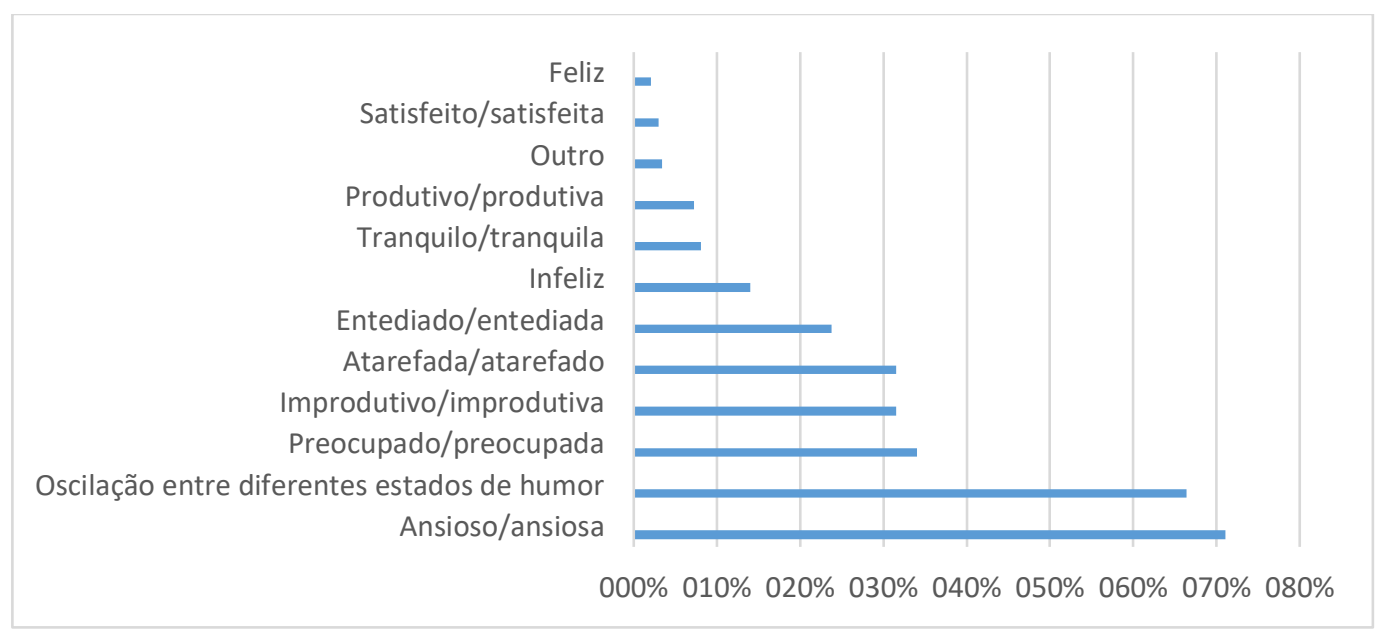

Fonte: Elaborada pelas autoras.

As situações estressantes que geram sofrimento emocional/psíquico entre os/as estudantes de terapia ocupacional, foram tratadas em questão aberta do questionário: 
"Considerando sua realidade (momento atual, estudante de terapia ocupacional, gênero, condições socioeconômicas, etc.) liste até cinco situações que deixam você estressada/estressado ou em sofrimento emocional". As respostas foram apresentadas em forma de itens ou por meio de frases e serão apresentadas na forma original para exemplificação das classes, conforme a recuperação feita pelo IRaMuTeQ.

O corpus elaborado com as respostas apresentou 5.182 ocorrências com 1.002 palavras. A palavra "falta" foi a mais frequente nas respostas ( $n=57)$, seguida de "estar" ( $n=39)$, "familiar" ( $n=37)$, "casa" ( $n=35)$ e "conseguir, curso e financeiro" ( $n=30)$. As centralidades destas palavras compõem a ideia, presente ao longo das respostas, da falta decorrente das perdas pelo distanciamento social, por estar em casa, junto à família e a preocupação em conseguir acompanhar e/ou finalizar o curso e preocupação com a situação financeira própria e/ou familiar, conforme ilustra uma das respostas: "relação em casa; improdutividade; falta de perspectiva quanto à situação financeira; falta de motivação; ansiedade em saber se vou conseguir me formar, se vou conseguir emprego na área".

A análise de CHD das palavras ativas produziu sete classes lexicais divididas em três grandes grupos. O Grupo A formado pelas classes 5 e 6, o Grupo B representado pelas classes 1,2 e 7 e o Grupo $C$ formado pela classe 3 e 4. Este resultado está demonstrado no dendrograma que apresenta também, a nuvem de palavras por classe (Figura 5). 
Figura 5. Dendograma das sete classes lexicais obtidas a partir da classificação hierárquica descendente sobre situações estressantes ou que geram sofrimento emocional/psíquico em estudantes de terapia ocupacional, no momento atual

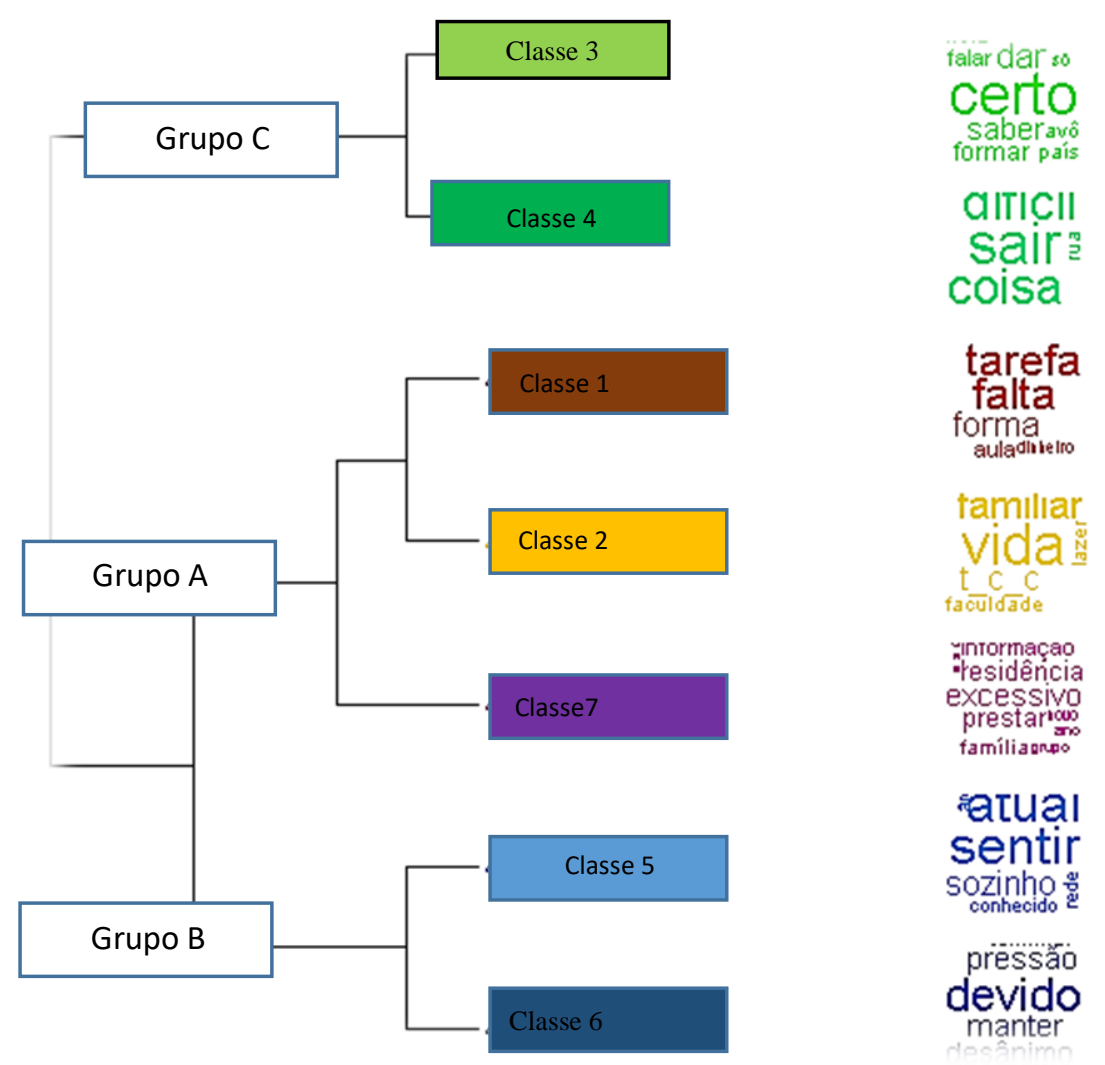

Fonte: Elaborada pelas autoras.

As classes lexicais receberam as seguintes nomeações: a) classe 1: Falta do cotidiano acadêmico; b) classe 2: Excesso de problemas; c) classe 3: Projeto (in)certo; d) classe 4: Não sair de casa; e) classe 5: Lidar com a situação; e f) classe 6: Estudante de terapia ocupacional; g) classe7: Falta de informação e sobrecarga. Os nomes das classes foram elaborados de forma subjetiva, baseando-se na composição das palavras mais predominantes, buscando-se representar as ideias de cada classe (CARVALHO et al,2020).

O grupo A, o mais representativo, totaliza 41\% dos segmentos de texto e reúne classes relacionadas a perdas acadêmicas e sobrecarga de problemas advindos da situação de pandemia do COVID 19. Os segmentos da Classe 1, denominada de "Falta do cotidiano acadêmico", de modo geral, referem-se às dificuldades enfrentadas, preocupações e incertezas e perdas decorrentes frente à modalidade de ensino à distância e distanciamento 
social, conforme exemplificado na resposta: "A demanda de conteúdo, a falta de aulas práticas, a consciência que aumentará um ano na duração da formação, a dificuldade com os meios tecnológicos, a incerteza quanto a um bom aproveitamento deste período remoto".

A Classe 2, denominada "Excesso de problemas" traz segmentos referentes a problemas surgidos e enfrentados neste momento de pandemia e distanciamento social, conforme ilustrado no relato: "Excesso de atividade remota do curso, perda de renda, desentendimento com parceiro e familiares, falta de lazer e vida social com amigos, quando acordada ter que enfrentar problemas familares e baixa condição de renda".

Ainda no grupo B, a Classe 7, "Falta de informação, incerteza e sobrecarga", traz palavras que indicam a incerteza e insegurança quanto a planos futuros relacionados à formação, formatura e após formatura, conforme relato a seguir: "Data de finalização do curso para prestar residência, preocupação excessiva com o futuro falta de informação da universidade, excesso de atividades assíncronas".

O Grupo $\mathrm{B}$, que pertence à mesma partição do Grupo A, conforme observa-se no dendograma (Figura 1), refere-se a ser estudante de terapia ocupacional, com projetos acadêmicos e de vida interrompidos e ter que lidar com a situação em que se encontra. Este grupo totaliza 21,7\% dos segmentos e compreende as classes 5 e 6 . A Classe 5, nominada "lidar com a situação", traz composição de palavras que indica a necessidade de lidar com a situação colocada pela mudança de cotidiano advinda da pandemia, isolamento social e seus desdobramentos. Como ilustração, seguem duas das respostas: "Não consigo produzir em casa, preciso de um emprego, as notícias sobre a pandemia nas redes sociais, distância de meus familiares e amigos, sofrimento frente a atual situação". "Isolamento, incapacidade em áreas tecnológicas para as aulas, situação financeira, perda de familiar, sofrimento por não poder estar perto dos meus familiares para poder se acolher".

Ainda no Grupo B, a Classe 6, nominada "Estudante de terapia ocupacional", traz o ser estudante de terapia ocupacional diante da situação enfrentada, conforme as respostas: "Pensar no mercado de trabalho, pensar que todo o meu esforço na universidade foi inútil, não fazer ideia quanto ao dia de amanhã como estudante de terapia ocupacional". "Falta de tempo para mim mesma, doença e perda de familiares, pressão para todos os lados, cobranças demasiadas e fora das minhas possibilidades no meu estudo". 
O Grupo C corresponde a uma partição independente, totaliza $27,3 \%$ dos segmentos de texto e compreende a Classe 3 e Classe 4. A Classe 3, nominada "Projeto (in)certo" indica as alunas e os alunos frente a incerteza e/ou frustração diante de alterações de projetos de vida e/ou acadêmicos, que foram alterados com a situação de pandemia. Como ilustração seguem duas respostas: "Quando não consigo fazer tudo que tinha planejado fazer, algumas disciplinas que não conversam com outras e nem com os projetos que participo, fico frustrada sem saber o que fazer". "Não formar em tempo certo de graduação, engordar e sedentarismo na pandemia, adiamento de projetos de pesquisa e extensão, não dar conta de tudo isso.

A Classe 4, nominada "Não sair de casa", traz as palavras que indicam o impacto do distanciamento, da impossibilidade de sair de casa e seus efeitos na vida da/do estudante. Segue uma das respostas que compõe segmento de texto desta classe: "Há dias que de tão sobrecarregada, nem no quintal de casa eu saio. Não ver o céu em um dia me deixa mal. Cobrança em relação à dedicação extrema nas disciplinas, considerando a complexidade da nossa profissão".

Em relação aos estados afetivo-emocionais de estudantes de terapia ocupacional, em período de pandemia e distanciamento social, a tabela 2 apresenta os resultados do DASS-21, onde verifica-se que $52,1 \%$ de estudantes apresentam algum índice de ansiedade, com 14,5\% de estudantes com índices severo e 2,1\% extremamente severo. Em relação à depressão, 47,9 \% de estudantes de terapia ocupacional apresentam algum índice de depressão, sendo que 22,2\% com índice moderado e 3,4 com índice severo. Já em relação ao estresse, verifica-se $62 \%$ com índices normais de estresse e, 23,1\% com estresse leve e $15,1 \%$ com estresse moderado. Não se observa índices que indiquem alguma severidade em relação ao estresse.

Tabela 2 - Estados emocionais de depressão, ansiedade e stress de estudantes de terapia ocupacional $(\mathrm{n}=235)$

\begin{tabular}{llcc}
\hline & & N & N\% \\
\hline & Normal & 112 & $47,9 \%$ \\
DASS_ansiedade / CATEGORIAS & Leve & 32 & $13,7 \%$ \\
& Moderado & 51 & $21,8 \%$ \\
& Severo & 34 & $14,5 \%$ \\
& Extremamente & 5 & $2,1 \%$ \\
\hline \multirow{3}{*}{ DASS_depressao } & severo & & $52,1 \%$ \\
& Normal & 122 & 52 \\
& Leve & $52,2 \%$ \\
& Moderado & 52 & $22,2 \%$ \\
DASS_stress & Severo & 8 & $3,4 \%$ \\
& Normal & 145 & $62,0 \%$ \\
& Leve & 54 & $23,1 \%$ \\
& Moderado & 35 & $15,0 \%$ \\
\hline
\end{tabular}

Fonte: Elaborada pelas autoras 
Foram relacionadas variáveis sociodemográficas e o rendimento acadêmico anterior à pandemia com os índices do DASS, conforme apresentado na Tabela 3. Como é possível observar, a correlação que apresentou significância foi "Rendimento acadêmico anterior à pandemia", enquanto as variáveis "Sexo", "Renda do núcleo familiar" e "Moradia anterior à pandemia", não apresentaram significância estatística na correlação com o DASS-21.

Tabela 3. Relação entre variáveis sociodemográficas e o DASS-21

\begin{tabular}{llccc}
\hline \multirow{2}{*}{ Variáveis } & \multicolumn{1}{c}{ Categorias } & \multicolumn{3}{c}{ DASS-21 } \\
\cline { 2 - 4 } & & Média & Desvio & Valor- \\
& & & Padrão & $\mathbf{p}$ \\
\hline Sexo & Feminino & 27,7 & 14,7 & \multirow{2}{*}{0,49} \\
\cline { 2 - 4 } & Masculino & 29,8 & 15,4 & \multirow{2}{*}{0,94} \\
\hline \multirow{3}{*}{ Renda do núcleo familiar } & Menos de 2 salários mínimos & 29,3 & 14,7 & \\
\cline { 2 - 4 } & Entre 2 e 3 salários mínimos. & 30,5 & 17,5 & \\
\cline { 2 - 4 } & Entre 3 e 5 salários mínimos. & 29,3 & 15,0 & \\
\cline { 2 - 4 } & Mais de 5 salários mínimos & 28,6 & 15,3 & \\
\hline Rendimento acadêmico & Bom & 35,6 & 16,8 & \\
\cline { 2 - 4 } anterior à pandemia & Regular ou ruim & 28,4 & 14,9 & \\
\hline
\end{tabular}

Fonte: Elaborada pelas autoras

\section{DISCUSSÃo}

Conforme apresentado, a mudança da situação de moradia de estudantes de terapia ocupacional que passaram a viver com familiares, é um dos efeitos concretos advindos das medidas adotadas de distanciamento social e consequente adoção de ensino a distância. Nesse sentido, retornar à casa de familiares nesta convivência prolongada pela situação do COVID19, pode demarcar a interrupção do processo de construção de autonomia e relações sociais que o morar sozinho ou com outras pessoas não familiares proporciona (OSSE e COSTA, 2011).

Além disso, no isolamento social, em que há aumento de convivência com familiares, nem sempre harmoniosa, em que todos dividem o mesmo espaço por maior tempo que o habitual, nem sempre é possível haver negociação pelo estabelecimento de limites de "espaço 
próprio", tanto em relação ao espaço físico como nas outras relações. Ao mesmo tempo, há mudança de rotina e perda ou redução do contato físico com outras pessoas fora do circuito familiar. Os resultados apresentados apontam este desgaste, ao trazerem o tédio, a preocupação, a improdutividade, a oscilação de humor e ansiedade (Gráfico 4) e ao relatarem situações estressantes que geram sofrimento emocional/psíquico. Tais resultados corroboram estudo de Bezerra et al (2020), realizado durante a pandemia com a população em geral, que destaca que o isolamento social tem gerado estresse no ambiente doméstico. Somado a isso, Lima (2020) aponta que o aumento do tempo de convivência doméstica também pode trazer o aumento de violência familiar, dirigida, na maioria das vezes, às mulheres e aos filhos.

Outra mudança enfrentada por este estudante em decorrência do confinamento, neste novo contexto, é a necessidade de adaptar-se ao ensino virtual, presentes nos relatos das dificuldades enfrentadas, preocupações e incertezas e perdas decorrentes frente à modalidade de ensino à distância. Diante da universalidade do direito à educação em período de necessário distanciamento e isolamento social, as IES buscam alcançar a totalidade dos seus alunos, com a oferta de ensino remoto e meios de acesso, com equipamentos necessários e acesso à internet (TOLEDO e PALUMBO, 2020). No entanto, a equidade de acesso e suporte material nem sempre garantem a efetivação do estudo remoto emergencial para todos os alunos e alunas. Neste processo, 21,7\% dos participantes têm dificuldade de acesso aos equipamentos tecnológicos e de internet e/ou falta de ambiente doméstico propício para os estudos.

Souza et al (2020) apontam que apesar da situação socioeconômica do estudante ser preditor central do acesso ao ensino virtual, outros fatores apresentam relevância, tal como a desmotivação e a influência do ambiente domiciliar, dificuldade de leitura de materiais digitais pela tela do computador ou smartphone/tablet e a impossibilidade de concentração dentro do ambiente domiciliar, além de ser considerada a inabilidade de alguns estudantes em manusear ferramentas tecnológicas.

Notar que são citados alguns aspectos positivos nessa modalidade de ensino, como possibilidade de escolha/adaptação do horário, maior tempo de dedicação aos estudos (Gráfico 3). Considerando que pesquisas anteriores apontam o curso de terapia ocupacional como trazendo sobrecarga de trabalho e atividades e consequente stress entre estudantes 
(GOVENDER et al, 2016; SANCHES et al, 2018; WITT et al, 2019), o ensino remoto pode ter trazido flexibilização de horários e tempo necessário para que respondam, sem exaustão, às demandas do curso. Tal hipótese pode ser reforçada nos índices de estresse apresentados, em que $62 \%$ de estudantes estão dentro do score de normalidade de stress e $38 \%$ estarem entre índices de stress leve a moderado.

O efeito negativo do ensino remoto emergencial com maior destaque foi: "Impedimento da vivência do cotidiano na universidade" (30,6\%). Somado a isso, o "Prejuízo na interação com professores, colegas, amigas e amigos do curso" (20,4\%), resulta em 51\% de estudantes que reclamam a presença da universidade e tudo que ela representa em suas vidas.

Mesmo que a internet e as mídias sociais tenham ajudado na manutenção dos relacionamentos com amigos e familiares no período de isolamento (PRIMO, 2020) e que a educação remota seja um valioso instrumento para manter o vínculo entre estudantes, professores (ARRUDA, 2020), estudo de Maia e Dias (2020) indica que o novo modo de viver está trazendo sofrimento psíquico e o desejo do retorno a uma rotina de aulas e estudo em companhia de seus pares. Segundo os autores, a falta da presença da universidade e de amigos, colegas e professores pode gerar ausência de apoio social e consequente sofrimento psíquico entre estudantes universitários. Realizada em Portugal, utilizando-se o DASS-21, a pesquisa de Maia e Dias (2020) detectou ansiedade, depressão e estresse entre estudantes universitários portugueses neste período pandêmico.

Assim como estudo de Maia e Dias (2020), os resultados aqui apresentados indicam índices de depressão, ansiedade e estresse entre as/os estudantes durante o período de distanciamento social. Ademais, os resultados apresentados são consistentes com resultados de pesquisas que utilizaram o mesmo instrumento e apontam que a população universitária está vulnerável ao desenvolvimento destes transtornos mentais (LARCOMBE et al, 2016; ASIF et al, 2020), além de estudos que apontam a presença destes tipos de sofrimento psíquico entre estudantes de terapia ocupacional (ARANTES, 2018; CAVESTRO e ROCHA, 2003).

Enquanto o DASS-21 indicou que estudantes terapia ocupacional apresentam algum grau de depressão, ansiedade ou stress, estados emocionais negativos estão presentes na autoavaliação do estado psíquico (Gráfico 4) feito pelas alunas e alunos, tais como : se sentindo ansiosas/ansiosos (71,1\%), com oscilação entre diferentes estados de humor $(66,4 \%)$, preocupadas/preocupados (34\%), improdutivas/ improdutivos (31,5\%), 
atarefadas/atarefados (31,5\%), entediadas/entediados (23,8\%), infelizes (14\%), ociosas/ociosos (12,3\%). É importante destacar que os instrumentos desta pesquisa foram utilizados para compreensão dos aspectos relativos da saúde mental desses estudantes, estando para além da proposta deste estudo a verificação diagnóstica.

Segundo revisão sistemática e metanálise de estudos realizados sobre os impactos da COVID-19 sobre a saúde mental de profissionais de saúde e da população em geral (LUOA et al, 2020), a prevalência geral de depressão na população neste período é de $28 \%$, a prevalência da ansiedade é de 33\% e de stress 40\%. Comparativamente com estes dados, os índices de depressão, ansiedade entre estudantes de terapia ocupacional, reportados neste estudo, são maiores, corroborando resultados de pesquisas em que ansiedade e depressão foram mais prevalentes em estudantes que outro grupo populacional (CAO, 2020; KECOJEVIC, 2020; WANG et al, 2020). Em relação ao estresse, as alunas e os alunos de terapia ocupacional apresentam índices semelhantes à população em geral. Releva-se o fato que 36,5\% de estudantes de terapia ocupacional apresentam índices de ansiedade entre severo e extremamente severo e 25,6\% com índices de depressão entre moderado e severo. Sem ter em conta o curso de graduação, destaca-se a importância do rastreamento desses estados emocionais no sentido de contribuir com o planejamento ações de prevenção e promoção da saúde mental de estudantes universitários.

O índice p de significância entre situação socioeconômica com o DASS-21 ( $p=0,94)$ não foi estatisticamente significativo, diferindo de resultados de outras pesquisas que consideraram este dado sociodemográfico (CAMPOS et al, 2020; WAHED e HASSAN, 2017). Este resultado chama a atenção, já que a preocupação com a situação econômica familiar está presente dentre as situações estressantes e/ou que geram sofrimento emocional/psíquico relatadas pelos participantes. Em relação a isso, Shah et al (2020) reforçam que a incerteza que as mudanças socioeconômicas, resultantes da pandemia nos coloca, é uma provável fonte de sofrimento psíquico. No entanto, verifica-se a escassez de produção em que se considera a situação socioeconômica na relação com os índices do DASS-21, reforçando-se a importância de novos estudos possam investigar esta questão.

Também a relação entre sexo e o DASS-21 não apresentou significância estatística ( $p=049$ ), contrapondo-se a estudos que em que o sexo feminino apresenta maior média, se comparada com o sexo masculino (SANTOS et al, 2020; WAHED e HASSAN, 2017. Patias et al 
(2016) discutem o fato de estudos que utilizam outros instrumentos, além do DASS-21, terem encontrado resultados semelhantes e sugerem que isso ocorre porque as mulheres exprimem suas emoções mais facilmente do que os homens. No entanto, a invariância entre estudantes do sexo masculino e estudantes do sexo feminino, apresentada neste estudo, corroboram resultados apresentados por Lu et al (2018) em pesquisa com estudantes universitários chineses e Martins et al (2019) com estudantes universitários brasileiros. Para Martins (2019) tal invariância permite a utilização do DASS-21 em ambos os sexos e viabiliza a realização de comparações diretas (escores médios ou prevalências). No entanto, os autores ressaltam a importância da análise de contextos e amostras ao se considerar tal índice de significância.

Em contrapartida encontrou-se significância na relação do DASS-21 com o rendimento acadêmico antes da pandemia ( $\mathrm{p}=0,01)$. Em relação ao rendimento acadêmico e o DASS-21, outros estudos que utilizam o instrumento em tempos de pandemia não analisaram este aspecto. No entanto, verifica-se que a questão acadêmica tangencia todos os resultados apresentados e mostra-se como tema central nos relatos apresentados na questão aberta que trata de situações de estresse e/ou sofrimento emocional/psíquico.

Em relação ao cotidiano acadêmico, as medidas de distanciamento geram como efeito no cotidiano destes/destas estudantes o sentimento de "falta", conforme a maior frequência da palavra ao longo das respostas à pergunta aberta do questionário. A lacuna deixada pelo atravessamento da pandemia no cotidiano desses/dessas estudantes não foi preenchida pelo estreitamento do convívio familiar e/ou pelas estratégias de ensino a distância. A lacuna parece ser reforçada pela preocupação com a formação, como a finalização do curso - para aqueles que cursam os períodos finais -, preocupações e incertezas e perdas decorrentes frente à modalidade de ensino à distância e distanciamento social, pela alteração de projetos de vida e/ou acadêmicos, pela incerteza e insegurança quanto a planos futuros relacionados à formação e após formatura, pela preocupação com problemas familiares, preocupação financeira própria e/ou familiar, pelas dificuldades enfrentadas.

Estudos com estudantes universitários sobre a saúde mental durante o período pandêmico, apontam a necessidade de rápida adaptação indo de ambiente presencial para on-line como fonte de fatores estressores e desencadeantes de sofrimento psíquico (WANG et $a l, 2020 ;$ CAO et al, 2020; SHAH et al, 2020). Além disso, os achados deste estudo em relação à preocupação com o futuro, com planos profissionais e de formação interrompidos vão ao 
encontro de resultados de Cao et al (2020), Muhamed et al (2020) e Shah et al (2020) em pesquisas com estudantes universitários.

\section{CONSIDERAÇÕES FINAIS}

Este estudo aponta impactos das medidas de distanciamento/isolamento social no cotidiano e saúde mental de estudantes de terapia ocupacional que, assim como outros estudantes universitários, passaram por mudanças em seu cotidiano, interrompendo processo importante de construção de autonomia, trocas, interação e formação acadêmica como haviam almejado. O isolamento, a distância da universidade e dos colegas, as aulas virtuais, a proximidade com os problemas familiares e financeiros, resultado do atravessamento da pandemia no fluxo da vida destes jovens, mostram-se como fatores desencadeantes de sofrimento psíquico entre este grupo.

Os resultados apontam que os índices de depressão, ansiedade e stress apresentados por estes/estas estudantes estão relacionados ao momento vivido, ao aproveitamento acadêmico antes da pandemia, independente do grupo ser composto, em sua maioria, por mulheres e de parte considerável se encontrar em situação socioeconômica precária, apesar deste último aspecto aparecer como preocupação deste grupo de estudantes.

A situação das perdas que a situação pandêmica impõe traz repercussão na saúde mental destes/destas jovens, como apresentado nesta pesquisa. Foi apontada a importância do rastreamento de estados emocionais no planejamento e elaboração de plano de cuidado, e prestação de assistência psicossocial, aos/ às estudantes. Destaca-se ainda a importância de investigação de dificuldades de estudantes no acompanhamento e aproveitamento de aulas nas modalidades síncronas e assíncronas utilizadas no ensino remoto emergencial, ou seja, faz-se necessário buscar conhecer os limites e possibilidades deste tipo de ensino para além dos limites impostos pela questão socioeconômica.

Como limitação deste estudo aponta-se a coleta de dados realizada por meio de informações autorreferidas fornecidas pelos estudantes, podendo haver a ocorrência de viés devido à interpretação dos alunos das questões. Em relação à utilização do DASS-21, apesar 
de ser um instrumento largamente utilizado em pesquisas sobre saúde mental de estudantes universitários, o estudo apontou lacunas quanto relação de variáveis sociodemográficas como sexo e situação socioeconômica, reforçando-se a importância de novos estudos que possam relevar tais questões.

\section{REFERÊNCIAS}

APPENZELLER, S.; MENEZES, F. H.; SANTOS, G. G. D.; PADILHA, R. F.; GRAÇA, H. S.; BRAGANÇA, J. F. Novos tempos, novos desafios: estratégias para equidade de acesso ao ensino remoto emergencial. Rev. bras. de ed. médica, $v$. 44, e0155, outubro/ $2020 . \quad$ Supl. 1. Disponível em: https://www.scielo.br/scielo.php?script=sci_arttext\&pid=S0100-55022020000500201\&lng=en\&nrm=iso . Acesso dia 10 de janeiro de 2021.

ARANTES, A. P. Qualidade de vida e transtorno mental comum em graduandos de ciências da saúde. 2018. 50f. Dissertação (Mestrado em Atenção à Saúde) - Programa de Pós-Graduação Stricto Sensu em Atenção à Saúde, Universidade Federal do Triângulo Mineiro, Uberaba, 2018.

ARAÚJO, F. J. O; LIMA, L.S. A.; CIDADE, P. I. M.; NOBRE, C. B.; ROLIM NETO, M. L Impact of Sars-Cov-2 And Its Reverberation in Global Higher Education and Mental Health. Psychiatry Res., vol. 288, 112977, June, 2020. Disponível em: https://www.sciencedirect.com/science/article/abs/pii/S0165178120307009. Acesso dia 10 de janeiro de 2021.

ARRUDA, E.P. Educação Remota Emergencial: elementos para políticas públicas na educação brasileira em tempos de COVID-19. Em rede, vol. 7, n. 1, novembro, 2020. Disponível em: https://www.aunirede.org.br/revista/index.php/emrede/\%20article/view/621. Acesso dia 10 de janeiro de 2021.

ASIF, S. ; MUDASSAR, A. ; SHAHZAD, T. Z. ; RAOUF, M. ; PERVAIZ, T. Frequency of depression, anxiety and stress among university students. Pakistan Journal of Medical Sciences, vol. 36, n. 5, p. 971-976, jul-aug, 2020. Disponível em: https://www.ncbi.nlm.nih.gov/pmc/articles/PMC7372668/. Acesso dia 10 de janeiro de 2021.

ABEP - ASSOCIAÇÃO BRASILEIRA DE EMPRESAS DE PESQUISA. Critério Brasil: 2009-2010. São Paulo: ABEP, 2009 Disponível »http://www.abep.org/criterio-brasil . Acesso dia 10 de janeiro de 2021.

em:

BORBA , P. L.; BASSI, B. G. C.; PEREIRA, B. P.; VASTERS, G. P.; CORREIA, R. L.; BARREIRO, R. G.. Desafios 'práticos e reflexivos' para os cursos de graduação em terapia ocupacional em tempos de pandemia. Cadernos Brasileiros de Terapia Ocupacional, vol. 28, n. 3, p.1103-1115, 2020. Disponível em: file:///C:/Users/Dell/Documents/279014846-1-PB.pdf. Acesso dia 10 de janeiro de 2021.

BRASIL. Lei n⿳o.10.861, de 14 de abril de 2004. Institui o Sistema Nacional de Avaliação da Educação Superior SINAES. Diário Oficial[ da] República Federativa do Brasil, Brasília, DF, 15 abr. 2004a. Seção 1. . Disponível em: http://www.planalto.gov.br/ccivil_03/_ato2004-2006/2004/lei/110.861.htm Acesso em 13 de abr. 2020.

BRASIL. Instituto Nacional de Estudos e Pesquisas Educacionais Anísio Teixeira (Inep). Censo da Educação Superior - Microdados do ano 2017: notas estatísticas. Brasília, 2018. Disponível em: http://inep.gov.br/microdados Acesso em: nov. 2019.

BRASIL. Portaria $\mathbf{n}^{\circ}$ 343, de 17 de março de 2020. Dispõe sobre a substituição das aulas presenciais por aulas em meios digitais enquanto durar a situação de pandemia do Novo Coronavírus -COVID-19. Brasília, DF: Ministério da Educação, 2020. Disponível em: http://www.in.gov.br/en/web/dou/-/portaria-n-343-de-17-demarco-de-2020-248564376. Acesso em 13 de abr. 2020. 
BEZERRA, A. C.; SILVA, C. E. M. D.; SOARES, F. R. G.; SILVA, J. A. M. D.. Fatores associados ao comportamento da população durante o isolamento social na pandemia de COVID-19. Ciência \& Saúde Coletiva, v. 25, p. 2411-2421, june, 2020. $\quad$ Disponível em: https://www.scielo.br/scielo.php?pid=S14131232020006702411\&script=sci_arttext\#: :text=0\%20conv\%C3\%ADvio\%20social\%20foi\%20o,no\%20sono\%2050\%2 C3\%25. . Acesso em 13 de abr. 2020.

CAMARGO, B. V.; JUSTO, A. M. (2013). IRAMUTEQ: um software gratuito para análise de dados textuais. Temas psicol. , Ribeirão Preto, v. 21, n. 2, p. 513-518, dez, 2013. Disponível em: http://pepsic.bvsalud.org/scielo.php?script=sci_arttext\&pid=S1413-389X2013000200016. Acesso em 20 de setembro de 2019.

CAMPOS, J. A. D. B. Early Psychological Impact of the COVID-19 Pandemic in Brazil: A National Survey. Journal of Clinical Medicine, v. 9, n. 9, p. 2976, 2020. Disponível em: https://www.mdpi.com/2077-0383/9/9/2976. Acesso em 10 de janeiro de 2021.

CAO, W.; FANG, Z.; HOU, G.; HAN, M.; XU, X.; DONG, The psychological impact of the COVID-19 epidemic on college students in China. Psychiatry Res. vol. 287, 112977 May, 2020; Disponível em: https://pubmed.ncbi.nlm.nih.gov/32229390/\#: :text=Results\%20indicated\%20that\%200.9\%25\%20of,\%2C\%20an d\%2021.3\%25\%20mild\%20anxiety.\&text=Moreover\%2C\%20having\%20relatives\%20or\%20acquaintances,CI\%20\% 3D\%202.377\%20\%2D\%203.804). Acesso em 24 de setembro de 2020.

CARVALHO, T. S.; MOTA, D. M.; SAAB, F. Utilização do software IRaMuTeQ na análise de contribuições da sociedade em processo regulatório conduzido pela Agência Nacional de Vigilância Sanitária. Vigil. sanit.

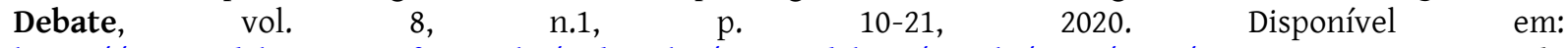
https://visaemdebate.incqs.fiocruz.br/index.php/visaemdebate/article/view/1429/1124. Acesso em $10 \mathrm{de}$ janeiro de 2021.

CAVESTRO, M.; ROCHA, F. L. Prevalência de depressão entre estudantes universitários. J Bras Psiquiatr, vol. 4 , n. 55, p. 5-8, 2013. Disponível em: https://www.scielo.br/scielo.php?script=sci_arttext\&pid=S004720852006000400001 . Acesso em 20 de setembro de 2019.

FERREIRA, C. M. G.; KLUTHCOVSKY, A. C. G. C.; CORDEIRO, T. M. G. Prevalência de Transtornos Mentais Comuns e fatores associados em estudantes de Medicina: um estudo comparativo. Rev Bras Educ Med. [On-line] Vol. 40, n. 2, p. 268-77, 2016. Disponível em: https://www.scielo.br/scielo.php?pid=S010055022016000200268\&script=sci_abstract\&tlng=pt Acesso em 10 de janeiro de 2021.

FONAPRACE - Fórum Nacional de Pró-Reitores de Assuntos Estudantis. VI Pesquisa do perfil socioeconômico e cultural dos estudantes de graduação das Instituições Federais de Ensino Superior. Universidade Federal de Uberlandia, 2018. Disponível em: http://www.andifes.org.br/wp-content/uploads/2017/11/Pesquisa-dePerfil-dos-Graduanso-das-IFES_2014.pdf. Acesso dia 10 de janeiro de 2021.

GONÇALVES, R.; AMBAR, A questão racial, a universidade e a (in) consciência negra. Lutas Sociais, São Paulo, vol.19 n.34, p.202-213, jan./jun. $2015 . \quad$ Disponível em: https://revistas.pucsp.br/index.php/ls/article/view/25767/pdf . Acesso dia 10 de janeiro.

GOVENDER, P.; MKHABELA, S.; HLONGWANE, M.; JALIM, K.; JETHA, C. OT student's experiences of stress and coping. S. Afr. j. occup. ther., Pretoria , v. 45, n. 3, p. 34-39, Dec. 2015. Disponível em: http://www.scielo.org.za/scielo.php?script=sci_arttext\&pid=S2310-38332015000300007\&lng=en\&nrm=iso . Acesso em 23 de fevereiro de 2021.

IBRAHIM, A. K.; KELLY, S. J.; ADAMS, C. E.; GLAZEBROOK, C. A systematic review of studies of depression prevalence in university students. Journal of Psychiatric Research, vol. 47, n. 3, p. 391-400, 2013. Disponível em: https://www.sciencedirect.com/science/article/abs/pii/S0022395612003573. Acesso dia 10 de janeiro de 2021.

JANSEN, K; MONDIN, T. C.; ORES; L. D. C.; SOUZA, L. D. D. M.; KONRADT, C. E.; PINHEIRO, R. T.; SILVA, R. A. D.Transtornos mentais comuns e qualidade de vida em jovens: uma amostra populacional de Pelotas, Rio Grande 
do Sul, Brasil. Cad Saúde Pública, vol. 27, n. 3, p. 440-8, 2011.Disponível em: https://www.scielo.br/scielo.php?script=sci_arttext\&pid=S0102-311X2011000300005 . Acesso dia 10 de janeiro de 2021.

KECOJEVIC, A..; BASCH, C. H.; SULLIVAN, M.; DAVI, N. K The impact of the COVID-19 epidemic on mental health of undergraduate students in New Jersey, cross-sectional study. PLoS ONE, vol. 15, n. 9, e0239696, September 30, 2020. Disponível em: https://journals.plos.org/plosone/article?id=10.1371/journal.pone.0239696 . Acesso dia 10 de janeiro de 2021.

LARCOMBE, W.; FINCH, S. ; SORE, R.; MURRAY, C. M ; KENTISH, S. ; MULDER, R. A ; LEE-STECUM, P.; BAIK, C. ; TOKATLIDIS, O.; WILLIAMS, D. A._Prevalence and socio-demographic correlates of psychological distress among students at an Australian university. Studies in higher education, Vol.41, n. 6, p.1074-1091, june, 2016. Disponível em: https://www.tandfonline.com/doi/abs/10.1080/03075079.2014.966072 . Acesso dia 10 de janeiro de 2021.

LEÃO, A. M. GOMES, I. P.; FERREIRA, M. J. M.; CAVALCANTI, L. P. D. G. . Ansiedade entre Estudantes Universitários da Área da Saúde de um Grande Centro Urbano do Nordeste do Brasil Revista Brasileira de Educação Médica, vol. 42, n..4, p. 55-65, 2018. Disponível em: https://www.scielo.br/scielo.php?pid=S010055022018000400055\&script=sci_arttext\&tlng=pt. Acesso em 10 de janeiro de 2021.

LOVIBOND, P. F.; LOVIBOND, S. H. The structure of negative emotional states: Comparison of the Depression Anxiety Stress Scales (DASS) with the Beck depression and anxiety inventories. Behaviour Research and Therapy, vol.33, n.3, p. 335-343, 1995.

LIMA, R. C. Distanciamento e isolamento sociais pela Covid-19 no Brasil: impactos na saúde mental. Physis, Rio de Janeiro , v. 30, n. 2, e300214, 2020 . Disponível em: http://www.scielo.br/scielo.php?script=sci_arttext\&pid=S0103-73312020000200313\&lng=en\&nrm=iso . Acesso em 11 Fevereiro de 2021.

LU, S.; HU, S.; GUAN, Y.; XIAO, J.; CAI, D.; GAO, Z.; MARGRAF, J. Measurement Invariance of the Depression Anxiety Stress Scales-21 across gender in a sample of Chinese university students. Front Psychol. Vol. 9, n. 2064, 2018. Disponível em: https://pubmed.ncbi.nlm.nih.gov/30429809/. Acesso em 11 Fevereiro de 2021.

LUOA, M.; GUO, L.; YU, M.; JIANG, W.; WANG, H. The psychological and mental impact of coronavirus disease 2019 (COVID19) on medical staff and general public - A systematic review and metaanalysis. Psychiatry Research, vol. 291, n. 113190, june 2020. Disponível em: https://www.ncbi.nlm.nih.gov/pmc/articles/PMC7276119/. Acesso em 11 Fevereiro de 2021.

NERDRUM, P.; RUSTØEN, T.; RØNNESTAD, M. H. Psychological distress among nursing, physiotherapy and occupational therapy students: A longitudinal and predictive study. Scandinavian Journal of Educational Research, vol. 53, n. 4, p. 363-378, 2009. Disponível em: https://www.tandfonline.com/doi/abs/10.1080/00313830903043133. Acesso em 20 de setembro de 2019.

MAIA, B. R.; DIAS, P. C. Ansiedade, depressão e estresse em estudantes universitários: o impacto da COVID-19. Estudos de Psicologia (Campinas), vol. 37, e200067, 2020. Disponível em: https://www.scielo.br/scielo.php?pid=S0103-166X2020000100504\&script=sci_arttext . Acesso em 21 de fevereiro de 2021.

MARTINS, B. G.; SILVA, W. R. D.; MAROCO, J.; CAMPOS, J. A. D. B.. Escala de Depressão, Ansiedade e Estresse: propriedades psicométricas e prevalência das afetividades. J. bras. psiquiatr., Rio de Janeiro , v. 68, n. 1, p. 3241, Mar. 2019. Disponível em: http://www.scielo.br/scielo.php?script=sci_arttext\&pid=S0047-

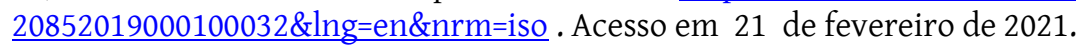

MEDEIROS, M. R. B.; CAMARGO, J. F.; BARBOSA, L. A. R.; CALDEIRA, A. P. Saúde mental de ingressantes no curso médico: uma abordagem segundo o sexo. Revista brasileira de educação médica, vol. 42, n. 3, p. 214-221, 2018. Disponível em: https://www.scielo.br/pdf/rbem/v42n3/1981-5271-rbem-42-3-0214.pdf . Acesso em 11 Fevereiro de 2021. 
MURAKAMI, K.; PANÚNCIO-PINTO, M. P.; DOS SANTOS, J. L. F.; DE ALMEIDA TRONCON, L. E. Estresse psicológico em estudantes de cursos de graduação da área da saúde : Rev Med (São Paulo), vol. 98, n. 2, p. 108-113. Disponível em: file:///C:/Users/Dell/Documents/154121-Texto\%20do\%20artigo-348220-1-10-20190507.pdf . Acesso em 20 de setembro de 2019 .

OMS- Organização Mundial da Saúde. OMS declara emergência de saúde pública de importância internacional por surto de novo coronavírus. OPAS/OMS, 2020. Disponível em: https://www.paho.org/bra/index.php?option=com_content\&view=article\&id=6100:oms-declara-emergenciade-saude-publica-de-importancia-internacional-em-relacao-a-novo-coronavirus\&Itemid=812. Acesso em 11 Fevereiro de 2021.

ORELLANA, J. D. Y.; RIBEIRO, M. R. C.; BARBIERI, M. A.; SARAIVA, M. D. C.; CARDOSO, V. C.; BETTIOL, H.; HORTA, B. L.. Transtornos mentais em adolescentes, jovens e adultos do Consórcio de Coortes de Nascimento brasileiras RPS (Ribeirão Preto , Pelotas e São Luís), 2020, Cadernos de Saúde Pública, vol. 36, n. 2, p. 1-13, 2020. Disponível em: https://www.scielosp.org/article/csp/2020.v36n2/e00154319/pt/. Acesso em 10 de janeiro de 2021.

OSSE, C. M. C.; COSTA, I. I. D. Saúde mental e qualidade de vida na moradia estudantil da Universidade de Brasília. Estudos de Psicologia, vol. 28, n.1, p. 115-122, 2011. Disponível em: https://www.scielo.br/scielo.php?pid=S0103-166X2011000100012\&script=sci_abstract\&tlng=pt . Acesso em 22 de janeiro de 2021.

PATIAS, N. D. Depression Anxiety and Stress Scale (DASS-21) - Short Form: Adaptação e Validação para Adolescentes Brasileiros. Psico-USF, Bragança Paulista, vol. 21, n. 3, p. 459-469, set./dez. 2016. Disponível em: https://www.scielo.br/scielo.php?script=sci_arttext\&pid=S1413-82712016000300459 . Acesso em 10 de janeiro de 2021.

PINHO, M. C. D. E. Uso de álcool e tabaco entre universitários de terapia ocupacional de uma universidade pública. 2018, 106 f. Dissertação (Mestrado em Saúde Coletiva)- Programa de Pós-Graduação em Saúde Coletiva - Universidade Federal do Espírito Santo - UFES, Vitória, 2018.

PRIMO, A. Afetividade e relacionamentos em tempos de isolamento social: intensificação do uso de mídias sociais para interação durante a pandemia de COVID-19. Comunicação \& Inovação, vol. 21, n. 47, 2020. Disponível em: https://seer.uscs.edu.br/index.php/revista_comunicacao_inovacao/article/view/7283. Acesso em: em 22 de janeiro de 2021.

SANCHES, B. P; SILVA, N. R.; SILVA, M. L. Avaliação do estresse em estudantes concluintes de Terapia Ocupacional. Cadernos Brasileiros de Terapia Ocupacional, vol. 26, n.1, p. 153-161, 2018. Disponível em: http://www.cadernosdeterapiaocupacional.ufscar.br/index.php/cadernos/article/view/1781/0. Acesso em 20 de setembro de 2019.

SANTOS, M. P. A. D; NERY, J. S.; GOES, E. F.; SILVA, A. D.; SANTOS, A. B. S. D.; BATISTA, L. E.; ARAÚJO, E. População negra e Covid-19: reflexões sobre racismo e saúde. Estudos Avançados, vol. 34, n. 99, p. 225-244, 2020. Disponível em: https://www.scielo.br/scielo.php?script=sci_arttext\&pid=S0103-40142020000200225. Acesso em: 14 de fevereiro de 2021.

SCHWARTZ, R., LENT, J., \& GEIHSLER, J. Gender and diagnosis of mental disorders: implications for mental health counseling. Journal of Mental Health Counseling, 33(4), 347-358, 2011. Disponível em: https://psycnet.apa.org/record/2011-23676-005 .Acesso em 21 de janeiro de 2021.

SHAH, S.M.A; MOHAMMAD, D.; QURESHI, M. F. H.; ABBAS, M. Z.; ALEEM, S.Prevalence, Psychological Responses and Associated Correlates of Depression, Anxiety and Stress in a Global Population, During the Coronavirus Disease (COVID-19) Pandemic. Community Ment Health J, vol. 57, p. 101-110, 2020. Disponível em: https://link.springer.com/article/10.1007/s10597-020-00728-y. Acesso em 21 de janeiro de 2021.

SILVA, A. C.; DA SILVA MARTINS, D.; SANTIAGO, A. T.; SANTOS, O. S.; PAES, C. J. O.; DA SILVA, A. C.; DE ARAÚJO, P. X. O impacto psicológico da pandemia de COVID-19 nos acadêmicos de medicina da região de Carajás. Braz. J. Hea. Rev, , v. 3, n. 6, p. 19731-19747, nov./dez. 2020. Disponível em: https://www.brazilianjournals.com/index.php/BJHR/article/view/22290 . Acesso em: 14 de fevereiro de 2021. 
TOLEDO, L. P.; PALUMBO, C. M. Q.T. A tecnologia como instrumento democratizador do direito à educação nos tempos da pandemia causada pela COVID-19. Revista Brasileira de Direitos e Garantias Fundamentais, vol. 6, n. 1, p.72-90, 2020. Disponível em: https://indexlaw.org/index.php/garantiasfundamentais/article/view/6640 . Acesso em 17 de fevereiro de 2021.

UNESCO - Organização das Nações Unidas para a Educação, a Ciência e a Cultura. CoVID-19: impact on Education. 2020. Disponível em: https://en.unesco.org/covid19/educationresponse . Acesso em: 11 maio 2020.

VALI, M.; MIRAHMADIZADEH, A.; MALEKI, Z.; GOUDARZI, F.; ABEDINZADE, A.; GHAEM, H. The Impact of Quarantine, Isolation, and Social Distancing on COVID-19 Prevention: A Systematic Review. Journal of health sciences and surveillance system, vol.8, n. 4, p.138-150, 2020. Disponível em: https://jhsss.sums.ac.ir/article_46955.html . Acesso em: 11 maio 2020.

VIGNOLA, R. C. B; TUCCI, A. M. Adaptation and validation of the depression, anxiety and stress scale (DASS) to Brazilian Portuguese. Journal of Affective Disorders, vol. 155, n. 1, p. 104-109, 2014.

WAHED, Y. A.; HASSAN, S. K. Prevalence andassociated factors of stress, anxiety and depression among medical Fayoum University students. Alexandria Journal of Medicine, vol. 53, n.1, p. 77-84, 2017. Disponível em: https://www.sciencedirect.com/science/article/pii/S2090506816000063. Acesso em 10 de janeiro de 2021.

WANG, C.; CHENG, Z.; YUE, X. G.; MCALEER, M. Risk Management of COVID-19 by Universities in China. J Risk Financial Manag., vol.13, n. 2, p.36, 2020. Disponível em: https://www.mdpi.com/1911-8074/13/2/36. Acesso em 10 de janeiro de 2021.

WANG, X.; HEGDE, S.; SON, C.; KELLER, B.; SMITH, A..; SASANGOHAR, F. Investigating mental health of US college students during the COVID-19 pandemic: cross-sectional survey study. Journal of medical Internet research, vol. 22, n. 9, e22817, 2020. Disponível em:

https://www.jmir.org/2020/9/e22817/. Acesso em 10 de janeiro de 2021.

WILliAMS, S. N.; ARMITAGE, C. J.; TAMPE, T.; DIENES, K. Perceptions and experiences of social distancing and social isolation during the COVID-19 pandemic: a UK-based focus group study. BMJ Open, , Vol.10, n. 7, July 2020. Disponível em: https://bmjopen.bmj.com/content/10/7/e039334. Acesso em 10 de janeiro de 2021.

WITT, P. A.; MONARENG, L.; ABRAHAM, A. A.; KOOR, S.; SABER, R. (2019). Resilience in occupational therapy students. South African Journal of Occupational Therapy, vol. 49, n. 2, p. 33-41. Disponível em: http://www.sajot.co.za/index.php/sajot/article/view/54. Acesso em 20 de setembro de 2019.

\section{(cc) BY}

Este trabalho está licenciado com uma Licença Creative Commons - Atribuição 4.0 Internacional. 